Check for updates

Cite this: Chem. Commun., 2019, 55, 4119

Received 26th February 2019, Accepted 12th March 2019

DOI: $10.1039 / c 9 c c 01624 d$

rsc.li/chemcomm

\section{MIL-53(Al) and $\mathrm{NH}_{2}-\mathrm{MIL-53(Al)}$ modified $\alpha$-alumina membranes for efficient adsorption of dyes from organic solvents $\dagger$}

\author{
Mohammad Amirilargani, (D *a Renaud B. Merlet, ${ }^{\mathrm{b}}$ Pegah Hedayati, ${ }^{\mathrm{a}}$ Arian Nijmeijer, ${ }^{\mathrm{b}}$ \\ Louis Winnubst, (D) ${ }^{b}$ Louis C. P. M. de Smet (D) ${ }^{* a c}$ and Ernst J. R. Sudhölter (iD ${ }^{* a}$
}

To the best of our knowledge, for the first time MIL-53(Al) and $\mathrm{NH}_{2}-$ MIL-53(Al) modified $\alpha$-alumina membranes are investigated for the adsorption of organic dyes from organic solvents. These new, modified membranes show excellent adsorption of high concentrations of Rose Bengal dye in methanol and isopropanol solutions.

Purification of non-aqueous mixtures has recently received much attention due to increased environmental concerns and the search for cleaner and more energy-efficient processes. ${ }^{1-3}$ Adsorption processes are key in many chemical industries due to their feasibility, ease of operation and high efficiency. Metal organic frameworks (MOFs) have emerged as a new class of materials due to their special structures, tunable properties and broad range of applications. ${ }^{4}$ MOFs are a class of crystalline open structures composed of inorganic units of metal ions or metal clusters as nodes and organic ligands as linkers with potential controllable molecular sieving properties in gas and liquid separations, ${ }^{5-8}$ owing to the relatively facile tunability of their pore size and pore structure. ${ }^{9,10}$ Among different MOFs, the MIL-53 series (MIL stands for Matériaux de l'Institut Lavoisier) have been considered as promising porous materials for organic dye separation. ${ }^{11-13}$ MIL-53 materials represent metal hydroxyterephthalates and are formed from trans bridging of corner-sharing $\mathrm{Me}^{3+} \mathrm{O}_{4}(\mathrm{OH})_{2}$ octahedra, bridged by 1,4-benzenedicarboxylate linkers. ${ }^{14}$ They possess a three-dimensional skeleton structure with large pores $c a .0 .85 \mathrm{~nm}$ in diameter and belong to the class of the so-called breathing MOFs, i.e. they switch reversibly

\footnotetext{
${ }^{a}$ Organic Materials and Interfaces, Department of Chemical Engineering, Delft University of Technology, Van der Maasweg 9, $2629 \mathrm{HZ}$ Delft, The Netherlands. E-mail:m.amirilargani@tudelft.nl, e.j.r.sudholter@tudelft.nl

${ }^{b}$ Inorganic Membranes, MESA ${ }^{+}$Institute for Nanotechnology, University of Twente, P.O. Box 217, 7500 AE Enschede, The Netherlands

${ }^{c}$ Laboratory of Organic Chemistry, Wageningen University \& Research, Stippeneng 4, 6708 WE Wageningen, The Netherlands. E-mail: louis.desmet@wur.nl

$\dagger$ Electronic supplementary information (ESI) available: Experimental details, additional structural pictures, XRD patterns, dye adsorption spectra, breakthrough curves and photographs of the membrane and collected samples. See DOI: $10.1039 / \mathrm{c} 9 \mathrm{cc} 01624 \mathrm{~d}$
}

between large-pore (lp) and narrow-pore (np) configurations upon adsorption and thermal or mechanical stimuli. ${ }^{14-16}$ For instance, the pore configuration of $\mathrm{NH}_{2}$-MIL-53(Al) changes from its np form (pore window area $\sim 3.4 \times 16.0 \AA^{2}$ ) at low $\mathrm{CO}_{2}$ pressure to its lp form (pore window area $\sim 8.5 \times 12.0 \AA^{2}$ ) upon increasing $\mathrm{CO}_{2}$ pressure. ${ }^{17}$ Most of the research applying MIL-53 for organic dye separation, has tended to focus only on their sieving properties, which do significantly improve the performance for dye separation from organic solvents via the organic solvent nanofiltration (OSN) process. Although extensive research has been carried out on the adsorption capacity of MOFs in aqueous media, ${ }^{18-20}$ only little attention has been paid to their adsorption capacities in organic media. This study therefore sets out to assess the MOF adsorption ability for dye removal from organic solvents.

Based on the above-mentioned considerations, we report now a unique morphology obtained for MIL-53(Al) and $\mathrm{NH}_{2}-$ MIL-53(Al) directly synthesized on $\alpha$-alumina membranes, resulting in excellent performance in terms of separating an organic dye, namely Rose Bengal (RB), from methanol solutions at an extremely high concentration of $200 \mathrm{mg} \mathrm{L}^{-1}$.

To the best of our knowledge, this is the first example of a MOF-based membrane adsorber successfully used for highly efficient removal of a hazardous organic dye from organic solvents. This provides a useful system for a wide range of potential applications, including solvent extraction in the pharmaceutical and bio industries. In our method of preparation, we have used the reactive seeding method, in which the $\alpha$-alumina support works as an inorganic source of aluminium ions that react with the added organic linker to form a seed layer. Next, MOFs were formed on top of this seed layer by further reaction with added aluminium ions and the organic linker (S1.3 and S1.4, ESI $\dagger$ ).

The field-emission scanning electron microscopy (FE-SEM) surface images of the bare and MOF-modified $\alpha$-alumina are shown in Fig. 1, clearly showing the unique structures of MIL53(Al) and $\mathrm{NH}_{2}$-MIL-53(Al). The MIL-53(Al) layer is formed by closely packed submicron particles, while the $\mathrm{NH}_{2}-\mathrm{MIL}-53(\mathrm{Al})$ 

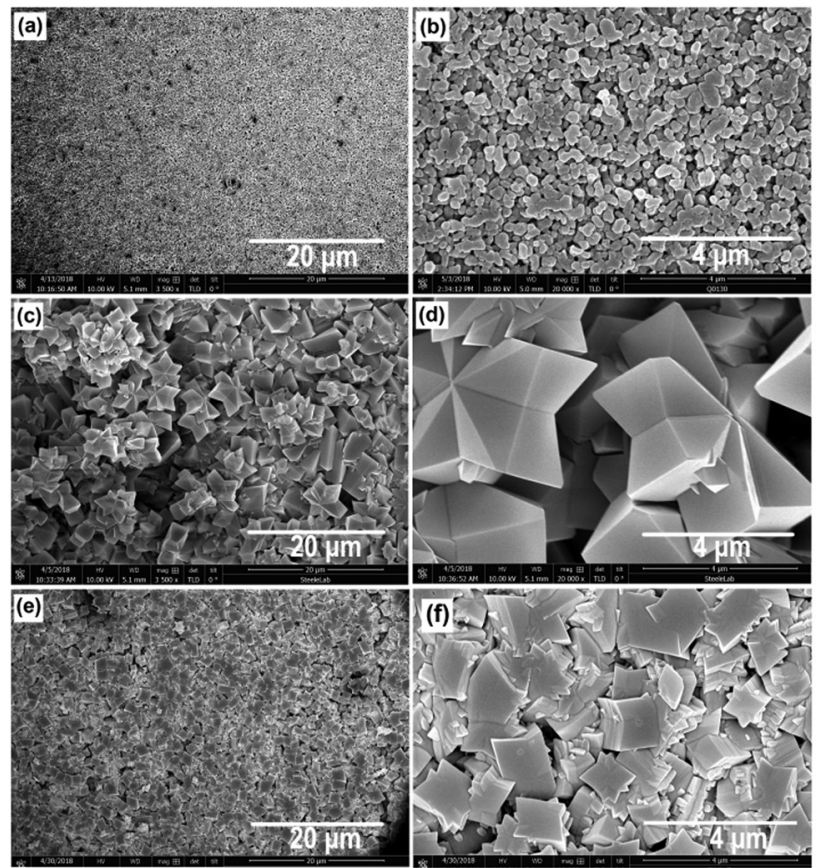

Fig. 1 Low and high magnification FE-SEM surface images of ( $a$ and $b$ ) $\alpha$-alumina, (c and d) MIL-53(Al) and (e and f) $\mathrm{NH}_{2}$-MIL-53(Al) membranes.

layer is formed by rather dense and compact packed submicron particles. In addition, Fig. $1 \mathrm{~d}$ and $\mathrm{f}$ show two different orientations of particles grown from the surface.

Furthermore, the MIL-53(Al) layer does not show any preferred growth direction, while the $\mathrm{NH}_{2}-\mathrm{MIL}-53(\mathrm{Al})$ layer is formed by numerous layers of MOFs grown in a layer-by-layer fashion (Fig. 1f and Fig. S1, ESI $\dagger$ ). These differences may be attributed to the different synthesis temperatures that were applied for MIL-53(Al) $\left(160{ }^{\circ} \mathrm{C}\right)$ and $\mathrm{NH}_{2}$-MIL-53 $\left(80{ }^{\circ} \mathrm{C}\right)$. A higher temperature speeds up the crystal growth rate, resulting in larger crystallites. ${ }^{21}$ Both $\mathrm{MIL}-53(\mathrm{Al})$ and $\mathrm{NH}_{2}$-MIL-53(Al) layers were well adhered to the $\alpha$-alumina support, where the MIL-53(Al) layer is almost $3 \times$ thicker compared to the $\mathrm{NH}_{2}$-MIL53(Al) layer (Fig. 2). This is in line with the faster crystallization at higher temperature.

The crystal structures obtained from the MOF powders isolated from the bottom of the autoclave and the MOFs synthesized on the alumina membranes were determined by X-ray diffraction (XRD) and the results are shown in Fig. S3, ESI. $\dagger$ Good agreement for both MOFs was obtained by comparison with their simulated XRD patterns (Fig. S4 and S5, ESI $\dagger$ ). In both MIL-53(Al) powders and membranes the np and $\mathrm{lp}$ configurations seem to coexist. The same behaviour was observed for the $\mathrm{NH}_{2}$-MIL-53(Al) obtained from the membranes, while the $\mathrm{NH}_{2}$-MIL-53(Al) powders mainly showed the np structure. Switching between lp and np structurers is observed upon water/solvent uptake, temperature changes or mechanical stress. ${ }^{14,22-24}$ Our results may indicate that some of the solvent molecules trapped in the pores of the MOF-modified membranes remained after the drying step and therefore both $\mathrm{np}$ and $\mathrm{lp}$ structures do coexist.
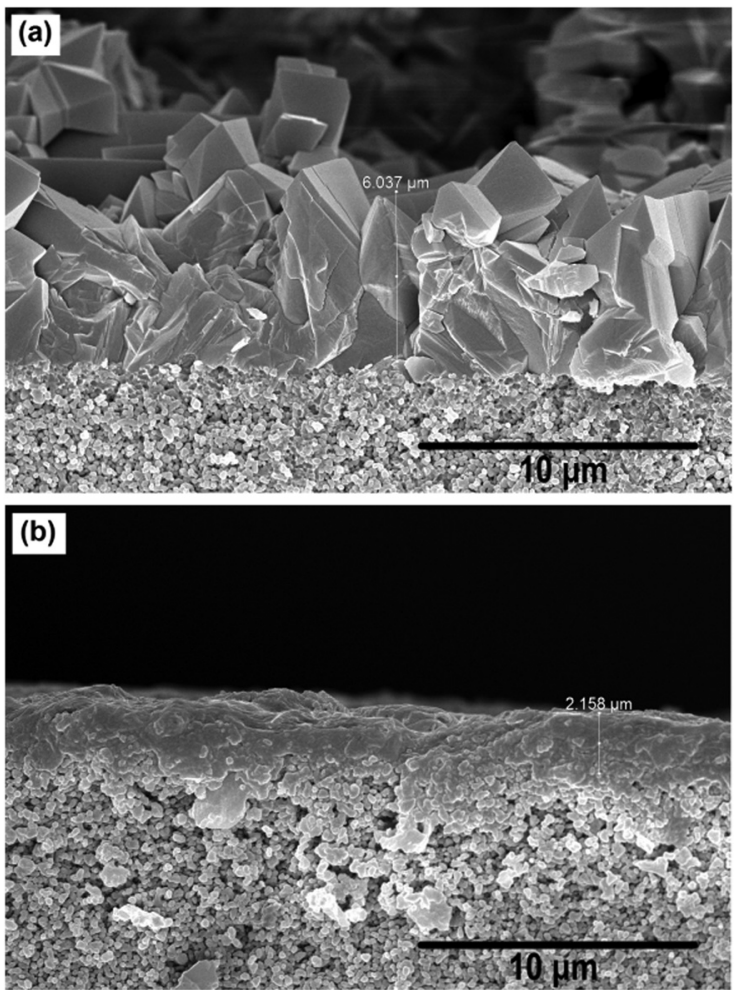

Fig. 2 Cross-sectional FE-SEM images of (a) MIL-53(Al) and (b) $\mathrm{NH}_{2}$-MIL53(Al) membranes on an $\alpha$-alumina support.

Next, we measured the breakthrough curves for adsorption of $\mathrm{RB}$ from methanol at the initial feed concentrations of $130 \mathrm{mg} \mathrm{L}^{-1}$ (Fig. 3). The feed side of the membrane cell was filled with $240 \mathrm{~mL}$ of solution and different $10 \mathrm{~mL}$ batches of permeant were collected from the permeate side. Fig. 3a shows the adsorption capacity of the unmodified membrane, which dramatically drops already after the collection of 2 samples (each of $10 \mathrm{~mL}$ ), while MIL-53(Al) and $\mathrm{NH}_{2}$-MIL-53(Al) modified membranes showed a much higher adsorption capacity. However, as shown in Fig. $3 \mathrm{c}$ the $\mathrm{NH}_{2}$-MIL-53(Al) modified membrane is still far outside the maximal adsorption capacity and after the collection of 17 samples the $C_{\text {permeate }} / C_{\text {feed }}$ is still $\sim 0$.6. In order to determine the maximal adsorption capacity, the cell was refilled with a fresh $\mathrm{RB} /$ methanol solution to continue the permeation experiments. To our surprise, the observed $C_{\text {permeate }} / C_{\text {feed }}$ value decreased after each performed refilling step. This was due to an increase of $C_{\text {feed }}$ after each refill. That increase originates from the release of RB bound to the MOF-modified membranes, when the external pressure is reduced. Regeneration of the MOF-modified membranes in this situation is thus very simple and might be of use in future applications. In addition, no significant changes were observed for the $\mathrm{NH}_{2}$-MIL-53(Al) modified membrane after two refilling steps and even after the collection of 34 samples, the $C_{\text {permeate }}$ $C_{\text {feed }}$ remained stable at $\sim 0.7$.

To find the maximal adsorption capacity and to avoid the release of bound $\mathrm{RB}$ to the MOF-modified membranes, filtration experiments were carried out using now an extremely high 

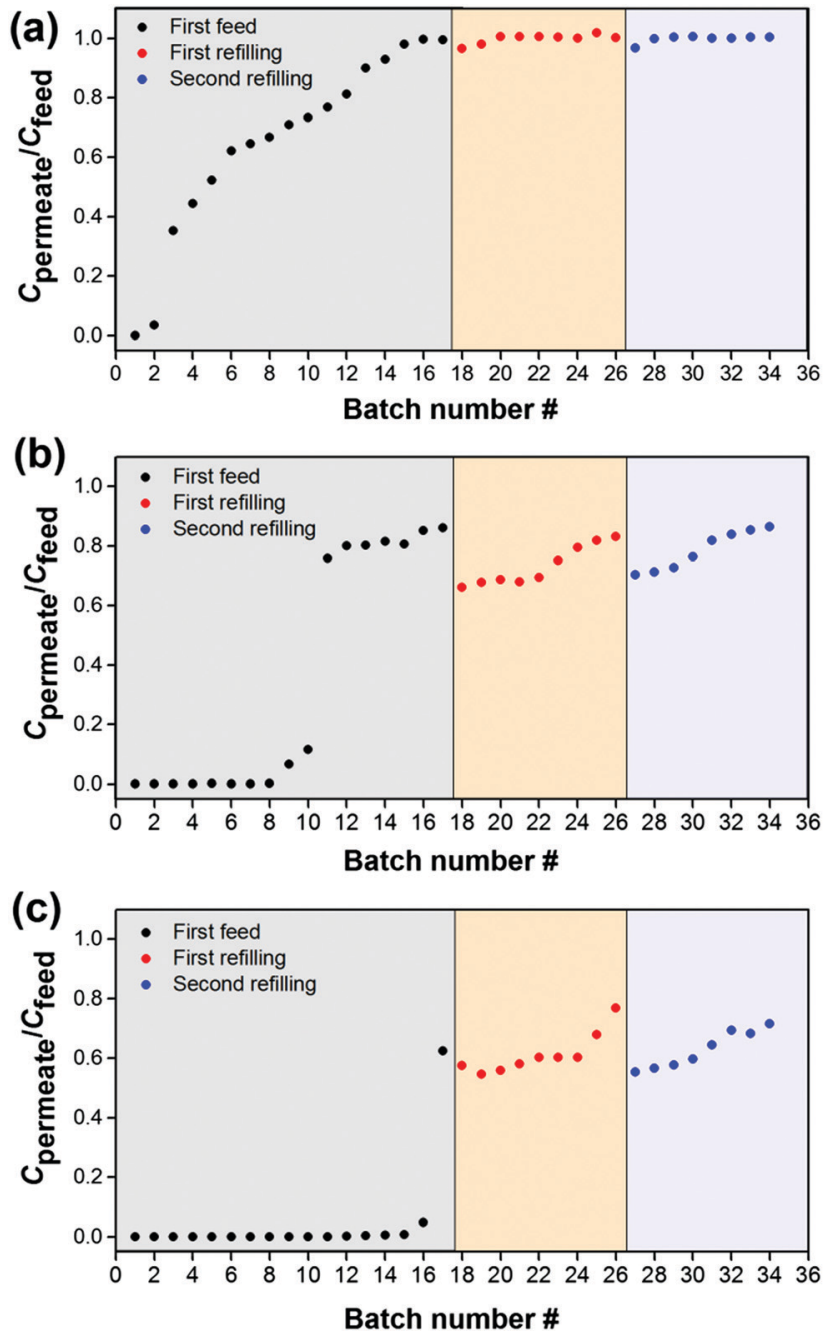

Fig. 3 Breakthrough curves showing the dynamic adsorption of RB from methanol (130 $\mathrm{mg} \mathrm{L}^{-1}$ ) using (a) $\alpha$-alumina, (b) MIL-53(Al) and (c) $\mathrm{NH}_{2}$-MIL53(Al) modified membranes. The colored region refers to the different filling steps.

concentration of RB in methanol and isopropanol $\left(200 \mathrm{mg} \mathrm{L}^{-1}\right)$. The observed breakthrough curves are shown in Fig. 4. For the unmodified $\alpha$-alumina membranes almost no RB is adsorbed from methanol. For the $\mathrm{NH}_{2}$-MIL-53(Al) modified membranes the amount of RB adsorbed from the methanol solution was nearly $70 \%$ higher compared to the amount adsorbed by MIL53(Al) modified membranes (37.6 versus $22.5 \mathrm{mg}$, respectively, Fig. $4 \mathrm{~b}$ and c). For both MOF-modified and unmodified $\alpha$-alumina membranes the adsorption capacity is slightly higher for RB removal from isopropanol compared to the one of methanol. This is most likely due to the higher viscosity of isopropanol compared to methanol, resulting in a longer contact time of the $\mathrm{RB} /$ isopropanol solution and consequently lower isopropanol permeability (Fig. 5). The size of the RB molecule is much larger than the pore sizes within both MOF crystallites, and therefore its adsorption can only occur on the available outer facets of the MOF crystallites (Scheme S1, ESI $\dagger$ ). ${ }^{12}$ Since the $\mathrm{NH}_{2}$-MIL-53(Al) modified membranes are more compact and composed of smaller MOF crystallites compared
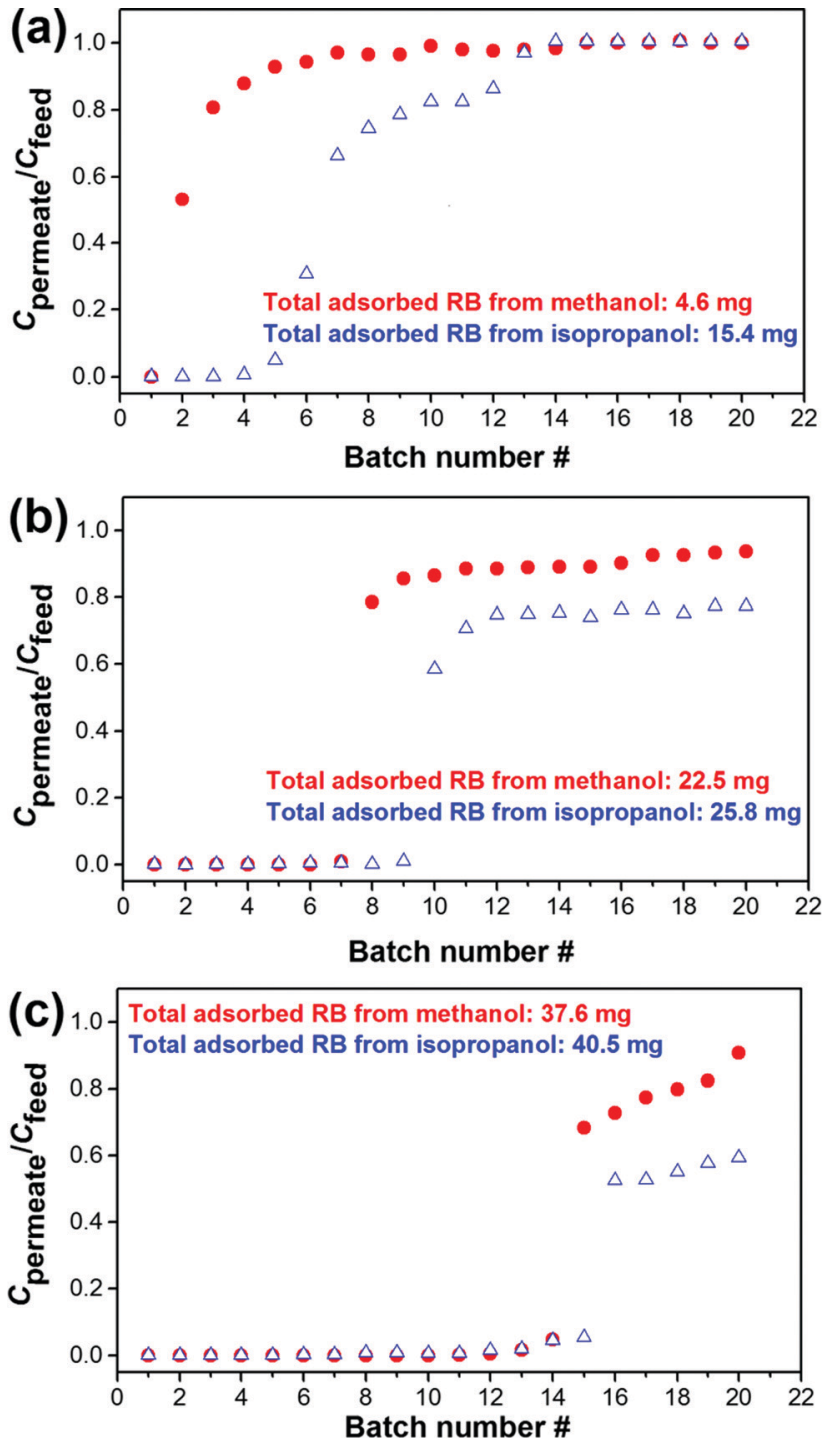

Fig. 4 Breakthrough curves showing the dynamic adsorption of RB from methanol and isopropanol (200 $\mathrm{mg} \mathrm{L}^{-1}$ ) using (a) $\alpha$-alumina, (b) MIL-53(Al) and (c) $\mathrm{NH}_{2}-$ MIL-53(Al) membranes.

to the MIL-53(Al) modified membranes (compare Fig. 1d and f), the adsorption of $\mathrm{RB}$ is higher due to a larger available facet area. In addition, the zeta potential distribution obtained for the MIL-53(Al) and $\mathrm{NH}_{2}$-MIL-53(Al) powders dispersed in methanol revealed a slightly positive zeta potential of $0.03 \mathrm{mV}$ for $\mathrm{NH}_{2}-\mathrm{MIL}-53(\mathrm{Al}) \mathrm{com}-$ pared to $-9.25 \mathrm{mV}$ for MIL-53(Al) (Fig. S10 ESI $\dagger$ ). This slightly more positive charge of $\mathrm{NH}_{2}-\mathrm{MIL}-53(\mathrm{Al})$ will contribute to the observed increase of the RB adsorption capacity since it is an anionic dye.

Fig. 5 shows the solvent permeability of the different investigated membranes during the dynamic adsorption of RB from methanol and isopropanol solutions. The solvent permeabilities of the MOF-modified membranes are lower compared to the unmodified $\alpha$-alumina membranes, and the thinner $\mathrm{NH}_{2}$-MIL53(Al) modified membrane still shows a relatively high methanol permeability of $6.9 \mathrm{~L} \mathrm{~m}^{-2} \mathrm{~h}^{-1} \mathrm{bar}^{-1}$. The state-of-the-art ceramic organic solvent nanofiltration membranes show methanol permeabilities in the range between 3.9 and $6.1 \mathrm{~L} \mathrm{~m}^{-2} \mathrm{~h}^{-1} \mathrm{bar}^{-1}, 5,26$ 


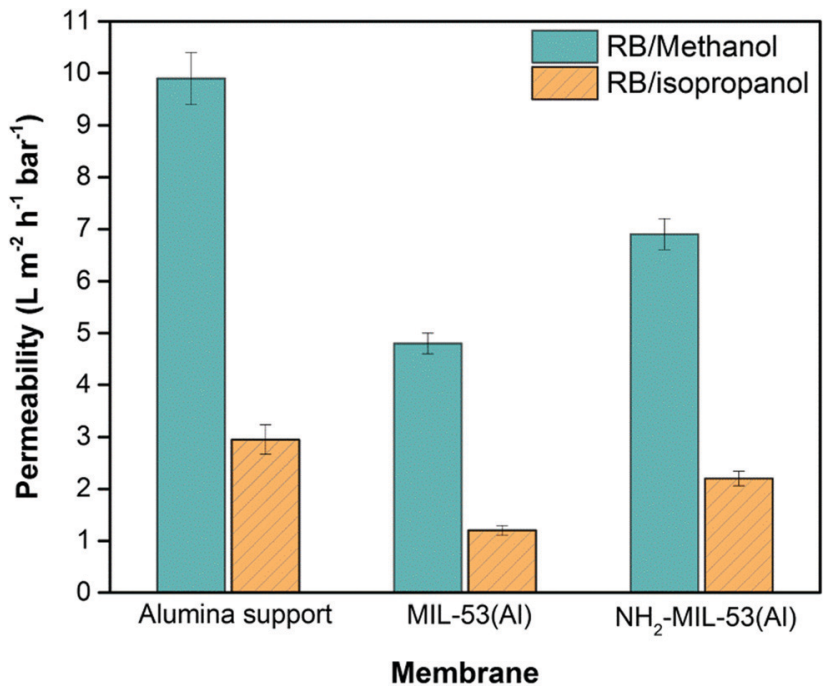

Fig. 5 Methanol and isopropanol permeabilities during the dynamic adsorption of RB.

from which we conclude that our $\mathrm{NH}_{2}$-MIL-53(Al) modified membranes combine a good RB adsorption with a high permeability.

In summary, we have shown that the unique structures of MIL-53(Al) and $\mathrm{NH}_{2}$-MIL-53(Al) modified membranes show a high $\mathrm{RB}$ adsorption and an easy release of bound $\mathrm{RB}$, in combination with a high methanol solvent permeability.

This work is part of a research program titled 'Modular Functionalized Ceramic Nanofiltration Membranes' (BL-20-10), which is taking place within the framework of the Institute for Sustainable Process Technology (ISPT, The Netherlands) and is jointly financed by the Netherlands Organization for Scientific Research (NWO, The Netherlands) and ISPT. LCPMdS acknowledges the European Research Council (ERC) for a consolidator Grant, which is part of the European Union's Horizon 2020 research and innovation programme (grant agreement No. 682444).

\section{Conflicts of interest}

There are no conflicts of interest to declare.

\section{Notes and references}

1 G. Szekely, M. F. Jimenez-Solomon, P. Marchetti, J. F. Kim and A. G. Livingston, Green Chem., 2014, 16, 4440-4473.
2 P. Marchetti, M. F. Jimenez Solomon, G. Szekely and A. G. Livingston, Chem. Rev., 2014, 114, 10735-10806.

3 J. F. Kim, G. Szekely, M. Schaepertoens, I. B. Valtcheva, M. F. Jimenez-Solomon and A. G. Livingston, ACS Sustainable Chem. Eng., 2014, 2, 2371-2379.

4 D.-M. Chen, J.-Y. Tian, Z.-W. Wang, C.-S. Liu, M. Chen and M. Du, Chem. Commun., 2017, 53, 10668-10671.

5 Y.-Y. Jia, Y.-H. Zhang, J. Xu, R. Feng, M.-S. Zhang and X.-H. Bu, Chem. Commun., 2015, 51, 17439-17442.

6 M. Amirilargani and B. Sadatnia, J. Membr. Sci., 2014, 469, 1-10.

7 G. Liu, V. Chernikova, Y. Liu, K. Zhang, Y. Belmabkhout, O. Shekhah, C. Zhang, S. Yi, M. Eddaoudi and W. J. Koros, Nat. Mater., 2018, 17, 283-289.

8 A. Sabetghadam, B. Seoane, D. Keskin, N. Duim, T. Rodenas, S. Shahid, S. Sorribas, C. L. Guillouzer, G. Clet, C. Tellez, M. Daturi, J. Coronas, F. Kapteijn and J. Gascon, Adv. Funct. Mater., 2016, 26, 3154-3163.

9 M. Eddaoudi, J. Kim, N. Rosi, D. Vodak, J. Wachter, M. O'Keeffe and O. M. Yaghi, Science, 2002, 295, 469-472.

10 M. O'Keeffe and O. M. Yaghi, Chem. Rev., 2012, 112, 675-702.

11 L. Zhu, H. Yu, H. Zhang, J. Shen, L. Xue, C. Gao and B. van der Bruggen, RSC Adv., 2015, 5, 73068-73076.

12 S. Basu, M. Maes, A. Cano-Odena, L. Alaerts, D. E. De Vos and I. F. J. Vankelecom, J. Membr. Sci., 2009, 344, 190-198.

13 S. Sorribas, P. Gorgojo, C. Téllez, J. Coronas and A. G. Livingston, J. Am. Chem. Soc., 2013, 135, 15201-15208.

14 M. Mihaylov, K. Chakarova, S. Andonova, N. Drenchev, E. Ivanova, A. Sabetghadam, B. Seoane, J. Gascon, F. Kapteijn and K. Hadjiivanov, J. Phys. Chem. C, 2016, 120, 23584-23595.

15 L. Chen, J. P. S. Mowat, D. Fairen-Jimenez, C. A. Morrison, S. P. Thompson, P. A. Wright and T. Düren, J. Am. Chem. Soc., 2013, 135, 15763-15773.

16 J. Y. Kim, L. Zhang, R. Balderas-Xicohténcatl, J. Park, M. Hirscher, H. R. Moon and H. Oh, J. Am. Chem. Soc., 2017, 139, 17743-17746.

17 A. Sabetghadam, X. Liu, M. Benzaqui, E. Gkaniatsou, A. Orsi, M. M. Lozinska, C. Sicard, T. Johnson, N. Steunou, P. A. Wright, C. Serre, J. Gascon and F. Kapteijn, Chem. - Eur. J., 2018, 24, 7949-7956.

18 H. Ting, H.-Y. Chi, C. H. Lam, K.-Y. Chan and D.-Y. Kang, Environ. Sci.: Nano, 2017, 4, 2205-2214.

19 C. Li, Z. Xiong, J. Zhang and C. Wu, J. Chem. Eng. Data, 2015, 60, 3414-3422.

20 Z. Jia, M. Jiang and G. Wu, Chem. Eng. J., 2017, 307, 283-290.

21 E. Haque, J. H. Jeong and S. H. Jhung, CrystEngComm, 2010, 12, 2749-2754.

22 K. Titov, Z. Zeng, M. R. Ryder, A. K. Chaudhari, B. Civalleri, C. S. Kelley, M. D. Frogley, G. Cinque and J.-C. Tan, J. Phys. Chem. Lett., 2017, 8, 5035-5040.

23 S. Couck, E. Gobechiya, C. E. A. Kirschhock, P. Serra-Crespo, J. JuanAlcañiz, A. Martinez Joaristi, E. Stavitski, J. Gascon, F. Kapteijn, G. V. Baron and J. F. M. Denayer, ChemSusChem, 2012, 5, 740-750.

24 E. Stavitski, E. A. Pidko, S. Couck, T. Remy, E. J. M. Hensen, B. M. Weckhuysen, J. Denayer, J. Gascon and F. Kapteijn, Langmuir, 2011, 27, 3970-3976.

25 H. Yang, N. Wang, L. Wang, H.-X. Liu, Q.-F. An and S. Ji, J. Membr. Sci., 2018, 545, 158-166.

26 N. F. D. Aba, J. Y. Chong, B. Wang, C. Mattevi and K. Li, J. Membr. Sci., 2015, 484, 87-94. 